\title{
Mathematical model for calculating the reliability of the characteristics of the designed trailer frame
}

\author{
Anvar Togaev*, and Abdulaziz Shermukhamedov \\ Tashkent State Transport University, Tashkent, Uzbekistan
}

\begin{abstract}
The article looks through the justification of the projected frame reliability characteristics of the trailer and its components. Given the desired level of reliability for the frame as a whole promoted calculation of the required parameters of reliability, including the probability of failurefree operation and mean time between failure elements of the trailer frame. The substantiation of indicators of reliability and durability of the projected trailer frame is carried out. Based on the calculation of the complexity factors of the frame elements, the required reliability indicators were calculated, including the probability of non-failure operating (PNFO) and the mean time between failures (MTBF). To assess the frame's durability, the formula has been proposed with the correction coefficient $\varepsilon_{\mathrm{c}}$, which can be used to calculate the resource of trailer frames made of elements of rolled steel of various grades. A mathematical model for evaluating the durability of the trailer frame is also proposed, based on the Weibull distribution and the power equation of the fatigue curve. A specific example shows the adequacy of the proposed formula to experimental values (The deviation from the experimental values of The Central Scientific Research Automobile and Automotive Engines Institute "NAMI" is $9 \%$ ).
\end{abstract}

\section{Introduction}

Ensuring reliability and durability is a complex task that covers a wide range of issues in the design, manufacture, and operation of a machine. Specific measures should be planned and carried out based on the standards for the reliability and durability of the machine's main components (assembly units). It is impossible to ensure the reliability of the machine as a whole. In the absence of scientifically based standards and requirements for the reliability and durability of specific components of the machine, significant material and labor costs for increasing the reliability of individual elements (parts) of the structure do not have a significant effect. As a result, it is impossible to determine the scientifically substantiated volume of a bench and other tests for the reliability of machine components and create an optimal method for assessing their results [1-9].

The importance of the calculated values of reliability standards in the manufacture of trailers and their structural elements is that they should serve as the main reference point in

\footnotetext{
* Corresponding author: anvar237@gmail.com
} 
the design process in the manufacture, including the development of methods of calculation and choice of testing equipment.

The problem of distribution in general requirements for the reliability of the frame elements can be formulated as follows: the desired reliability index for the frame consisting of $n$ elements is set; you need to determine what changes should have the norm of each element. Techniques given in the research are applied to solve this type of problem [1-4].

The most comprehensible to our calculations is the method based on the utility theory in the distribution requirements for non-failure operation of components of the system based on the account of their complexity [4].

However, as the analysis of these methods has shown, due to the requirements, assumptions, and limitations adopted in them, it is impractical or impossible to use them in full when calculating the reliability and durability indicators of the designed trailer.

\section{Materials and Methods}

According to [1-4], depending on the available a priori information, the standard values of the required indicators of the constituent elements of the product can be determined in different ways, the main methods, and principles that can be applied in calculating the reliability and durability standards of some elements of the projected trailer; among them:

uniform distribution method;

significance distribution method;

the method of distributing the requirements for the reliability of system elements in proportion to the costs of their repair;

sensitivity method;

Lagrange multiplier method;

method of distribution of reliability requirements, taking into account the importance of the element;

method of distribution of reliability requirements, taking into account the relative vulnerability of elements;

method for determining the standard values of the reliability indicators of the component parts of the product, taking into account the use of a priori information about the change in their output parameters;

reliability distribution taking into account the weighting factor;

determination of requirements for the reliability of components, based on the achieved level of their reliability and laboriousness of eliminating failures;

distribution of reliability requirements using the principle of equality of possible losses in operation for each component of the machine, taking into account the complexity and share of its work;

method of distribution of requirements for the mean operating time between failures of component elements of a product in the absence of a priori information;

requirements for the reliability of component elements, taking into account the data of operational tests of machines or their analogues;

application of the theory of utility in the distribution of requirements for the reliability of the system's constituent elements based on taking into account their complexity.

The importance of the calculated values of the standards in the production of trailers and their structural elements is because they should serve as the main guideline in designing the technological process for the manufacture of trailers, including the development of calculation methods and selection of equipment for testing. It is important for the consumer that the trailer has the required performance over a long period of operation.

In this connection, there was a task in view - to develop a way of maintaining the demanded level of non-failure operation of the trailer. 
It is known that the probability $P_{\mathrm{s}}$ of non-failure operation (PNFO) of any difficult technical system consisting of $n$ elements is calculated by the formula

$$
P_{\mathrm{S}}=\prod_{i=1}^{n} P_{\mathrm{ei}}
$$

where $P_{\mathrm{e} 1}, P_{\mathrm{e} 2}, P_{\mathrm{e} 3}, \ldots, P_{\mathrm{en}}$ is according to the probability of non-failure operating (PNFO) of each individual element of the system.

As the trailer is a difficult technical system consisting of many elements, an estimation of its reliability under the formula (1) - a difficult mathematical problem.

According to the formula (1) reliability of a system is always below the reliability of its most unreliable element.

At designing the trailer and its basic components, designers have the information, allowing to make it the structurally-functional scheme (SFS) on which it is possible to establish the complexity of a projected design. Therefore, we suggest carrying out calculations on rationing of reliability of elements of a design of the trailer according to its hierarchy structurally-functional scheme (SFS) (see Figure 1). The specification of reliability of an element of the higher level of the hierarchy is the specification of reliability for elements of the subordinate level. Generally, at the set demanded indicator of reliability for the system from $n$ elements, the account of such sign as the complexity of components can provide objective distribution of requirements to reliability. Considering that the more complex the element, the more difficult it is to ensure the value of $P_{\mathrm{ei}}$, the required probability of non-failure operating (PNFO) of elements calculated by the formula

$$
P_{\mathrm{ei}}=P_{\mathrm{S}}^{K_{\mathrm{i}}}
$$

where $K_{\mathrm{i}}$ is the complexity coefficient characterizing the quantitative measure of the complexity of the $i$-th basic element of the trailer; $P_{\mathrm{s}}$ is required the probability of nonfailure operating (PNFO) of the designed trailer [4-13].

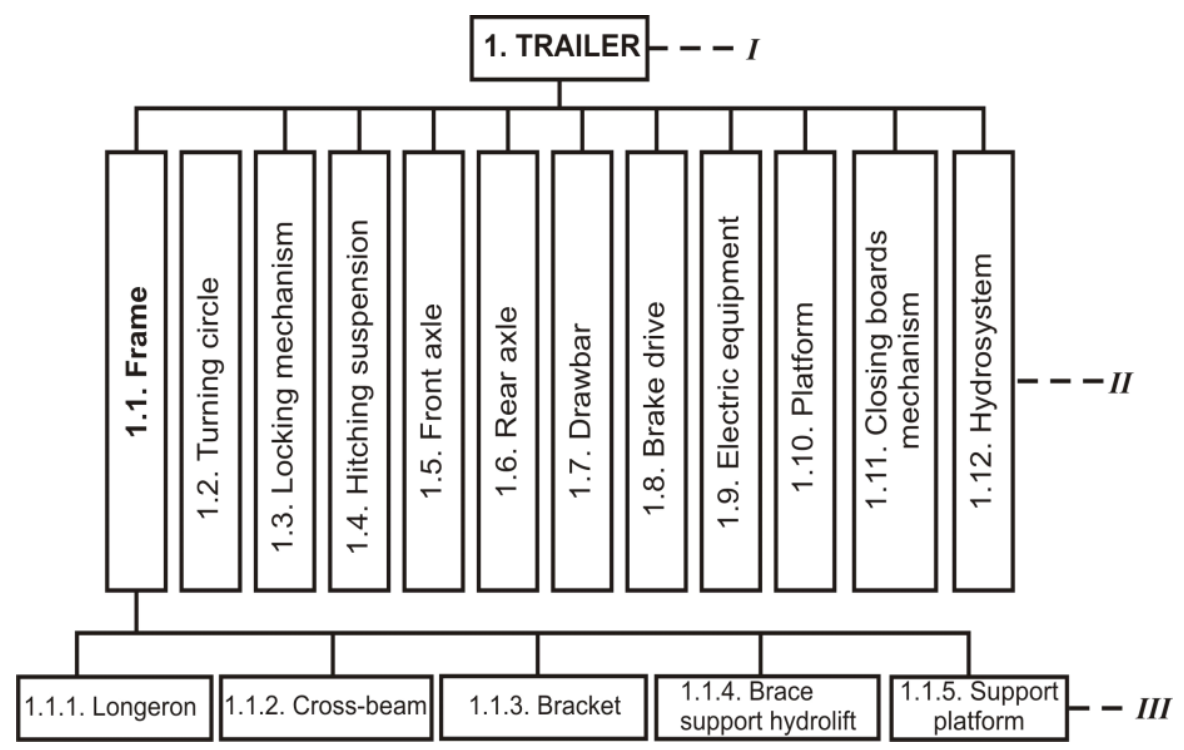

Fig 1. SFS of the trailer: $I, I I, I I I-$ hierarchy levels 
The complexity is defined by the expression:

$$
K_{\mathrm{i}}=\frac{2(n-i+1)}{n(n+1)} ; 0<K_{\mathrm{i}}<1, \sum_{i=1}^{n} K_{\mathrm{i}}=1,
$$

where $n$ and $i$ is the number of elements and the number of the element in the ranked series.

It is obvious that an element of greater complexity must correspond to a lower level of reliability [according to formula (1)].

This method of calculation $P_{\mathrm{ei}}$ is most comprehensible at the design stage of trailers in the absence of operational data about their refusals.

The calculation of $P_{\mathrm{ei}}$ of the components of the designed trailer, from which it is possible to proceed to the determination of the mean time between failures (MTBF) $t_{\mathrm{ei}}$ is carried out in the following sequence:

it is appointed the probability of non-failure operating (PNFO) $P_{\mathrm{s}}$ for the trailer in whole (in many cases $P_{\mathrm{s}}$ of the trailer it is equal $P_{\mathrm{s}}$ a tractor towing the trailer);

composed of the structurally-functional scheme (SFS) of the trailer;

it produced a ranking of the main constituent elements of the respective levels of the hierarchy of the structurally-functional scheme (SFS) trailer; using the formula (3), values of coefficients are defined $K_{\mathrm{i}}$;

by the formula (2), there are demanded values $P_{\mathrm{ei}}$ for each level of the trailer structurally-functional scheme (SFS);

at known dot values $P_{\mathrm{ei}}$ and the kind of the law of distribution mean time between failures (MTBF) $t_{\mathrm{ei}}$ the basic components of the trailer are defined;

$$
\prod_{i=1}^{n} P_{\mathrm{ei}}
$$

conducting an assessment resulting from $P_{\mathrm{s}}$ by Kolmogorov-Smirnov goodness-of-fit test:

$$
\lambda=\max \left|\prod_{i=1}^{n} P_{\mathrm{ei}}-P_{\mathrm{S}}\right| .
$$

For the illustration of the distribution approach of requirements set forth above on reliability between trailer components, we will consider an example of calculation $P_{\text {ei }}$ for $I I$ level of the hierarchy structurally-functional scheme (SFS) of the projected trailer:

- Demanded the probability of non-failure operating (PNFO) of the trailer it is appointed based on the given analogues of the similar trailers used in other industries, $P_{s}=0.7$;

- The structurally-functional scheme (SFS) for II-level of hierarchy is represented in the design of the trailer in the kind presented in figure 1;

- Ranging of the basic components of $I I$-level of the hierarchy structurally-functional scheme (SFS) of the trailer carried out according to their complexity on number of elements of $i$-component (table 1, columns 3,4);

- Complexities $K_{\mathrm{i}}$ of elements of the construction of the trailer (table 1, column 5) are defined;

- Demanded the probability of non-failure operating (PNFO) of elements of II-level of hierarchy, $P_{\text {ei }}$, (table 1, column 6) are defined. 
Table 1. The calculation PNFO of basic elements of $I I$-level SFS of the trailer

\begin{tabular}{|c|c|c|c|c|c|c|}
\hline № & $\begin{array}{c}\text { The name of assembly } \\
\text { units (II-level of } \\
\text { hierarchy SFS of the } \\
\text { trailer) }\end{array}$ & 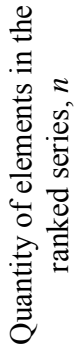 & 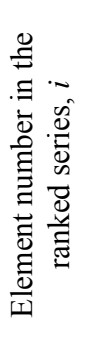 & 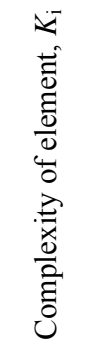 & 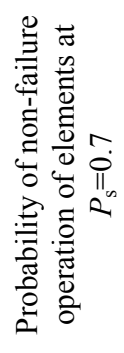 & 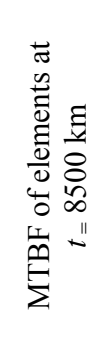 \\
\hline 1 & 2 & 3 & 4 & 5 & 6 & 7 \\
\hline 1.1 & Frame & 18 & 6 & 0.090 & 0.968 & 18120.0 \\
\hline 1.2 & Turning circle & 1 & 12 & 0.013 & 0.995 & 28951.1 \\
\hline 1.3 & Locking mechanism & 2 & 11 & 0.026 & 0.991 & 25003.2 \\
\hline 1.4 & Hitching suspension & 9 & 8 & 0.046 & 0.977 & 19695.6 \\
\hline 1.5 & Front axle & 38 & 2 & 0.141 & 0.951 & 16281.2 \\
\hline 1.6 & Rear axle & 35 & 3 & 0.128 & 0.955 & 16632.8 \\
\hline 1.7 & Drawbar & 9 & 9 & 0.051 & 0.982 & 20983.7 \\
\hline 1.8 & Brake drive & 21 & 5 & 0.103 & 0.964 & 17582.2 \\
\hline 1.9 & Electric equipment & 13 & 7 & 0.077 & 0.973 & 18968.1 \\
\hline 1.10 & Platform & 45 & 1 & 0.154 & 0.947 & 15944.1 \\
\hline 1.11 & $\begin{array}{l}\text { Closing boards } \\
\text { mechanism }\end{array}$ & 8 & 10 & 0.038 & 0.987 & 22784.0 \\
\hline 1.12 & Hydrosystem & 24 & 4 & 0.115 & 0.960 & 17151.5 \\
\hline
\end{tabular}

Calculations of the mean time between failures (MTBF) of elements $t_{\mathrm{ei}}$ is connected with the knowledge of laws of distribution of a random variable - refusals. The calculation of the mean time between failures (MTBF) of elements $t_{\mathrm{ei}}$ of the construction of the projected trailer is carried out in the following sequence:

1. Laws of distribution of operating time to the full or between refusals for the trailer and elements of its construction are passed. It is necessary to notice that distribution Weibull takes the central place in researching characteristics of reliability of vehicles and their units. Operating time to failure or the refusal of many restored and nonrestorable products at which refusal comes because of fatigue failure submit to this distribution. The continuous random variable $t$ is called as distributed under law Weibull if it the probability of non-failure operating (PNFO), it is calculated on the equation:

$$
P(t)=\mathrm{e}^{-\left(\frac{t-c}{a}\right)^{b}}
$$

where $a$ is scale parameter; $b$ is form parameter; $c$ is shift parameter.

2. The procedure of calculating the probability of non-failure operating (PNFO) $-P_{\mathrm{ei}}$ basic elements of constructing a certain level of the hierarchy structurally function scheme (SFS) of the projected trailer is spent. The current value of operating time $t$, corresponding to, for example, $\mathrm{P}_{s}=0.7$ (for the trailer), can be determined from equation (4). Calculated the probability of non-failure operating (PNFO) of elements of II-level of the hierarchy structurally function scheme (SFS) of the projected trailer corresponds, to for example current value $t=8500 \mathrm{~km}$. Conditionally accepting the version that is operating time to the first failure or between failures of elements of II-level of the hierarchy structurally function 
scheme (SFS) of the projected trailer also submit to the law of distribution Weibull, their calculation $t_{\mathrm{a} . \mathrm{i}}$ is carried out.

For example, it is required to define $t_{\mathrm{a} . \mathrm{i}}$ an element No. 1.1 - frame in number of ranking series (see table 1) using the equations (4) at accepted coefficient of variation $V=0.281$, parameter $b=4.0$ and Weibull coefficient $K_{\mathrm{b}}=0.906$, conditionally we accept, that parameter of shift $c=0$, then at $t=8500 \mathrm{~km}, P_{\mathrm{ei}}=0.968$ (see table 1 , column 6) we have:

3. $a=20000 \mathrm{~km} ; t_{\mathrm{a} .1 .1}=a \cdot K_{\mathrm{b}}=20000 \cdot 0.906=18120 \mathrm{~km}$.

Similarly are defined $t_{\text {a.i }}$ for other elements of $I I$-level of hierarchy SFS of the projected trailer, according to their place in the ranked series.

The results of calculations $P_{\mathrm{ei}}$ and $t_{\mathrm{a} . \mathrm{i}}$ are presented in table 1 (columns 6,7 ).

The calculation of the mean time between failures (MTBF) of elements of III-level hierarchy SFS of the projected trailer is carried out similarly. The results of calculation of indicators of non-failure operation of elements of the frame (see figure 1, III-level of the hierarchy structurally function scheme (SFS) of the trailer) are presented in table 2.

Table 2. Calculation of indicators of non-failure operation of elements of III-level of hierarchy SFS of the trailer (frame elements)

\begin{tabular}{|c|c|c|c|c|c|c|}
\hline № & $\begin{array}{l}\text { The name of } \\
\text { assembly } \\
\text { units (II-level } \\
\text { of hierarchy } \\
\text { SFS of the } \\
\text { trailer) }\end{array}$ & $\begin{array}{l}\text { Quantit } \\
\text { y of } \\
\text { elemen } \\
\text { ts in } \\
\text { the } \\
\text { ranked } \\
\text { series, } \\
n\end{array}$ & $\begin{array}{c}\text { Element } \\
\text { number } \\
\text { in the } \\
\text { ranked } \\
\text { series, } i\end{array}$ & $\begin{array}{c}\text { Complexity } \\
\text { of element, } \\
K_{\mathrm{i}}\end{array}$ & $\begin{array}{c}\text { PNFO } \\
\text { of } \\
\text { elements } \\
\text { at } \\
P_{\mathrm{s}}=0.7\end{array}$ & $\begin{array}{c}\text { MTBF } \\
\text { of } \\
\text { elements } \\
\text { at } \\
t=8500 \\
\text { km }\end{array}$ \\
\hline 1 & 2 & 3 & 4 & 5 & 6 & 7 \\
\hline 1.1.1 & Longeron & 2 & 3 & 0.20 & 0.87 & 26838 \\
\hline 1.1 .2 & Cross-beam & 7 & 2 & 0.27 & 0.83 & 24999 \\
\hline 1.1 .3 & Bracket & 20 & 1 & 0.33 & 0.80 & 23889 \\
\hline 1.1 .4 & $\begin{array}{c}\text { Brace support } \\
\text { hydrolift }\end{array}$ & 2 & 5 & 0.07 & 0.95 & 34496 \\
\hline 1.1 .5 & Support platform & 2 & 4 & 0.13 & 0.92 & 30548 \\
\hline
\end{tabular}

These calculated values should be provided during the production of these elements and confirmed by appropriate tests on stands.

Thus, by the offered design procedure of indicators, reliability of the trailer elements is possible on the design stage at demanded of the mean time between failures (MTBF) for the trailer as a whole, to calculate the mean time between failures (MTBF) of elements of the bottom levels structurally function scheme (SFS), which should be the basic reference point by their manufacture.

The calculated specifications of the mean time between failures (MTBF) elements of the trailer should be confirmed by results accelerated bench or field tests.

Consider a technique of improving the tests concerning to manufacture of frame trailers.

The literature [14] data that at the expense of frequency increase of dynamic loadings influence at the frame construction acceleration of fatigue tests in 18 times and more is reached are cited.

The obstacles that simulate real conditions are removable to restructure the road for various tests (depending on the roughness height). For testing, tractor-trailers are used for 
fatigue resistance obstacle height 50, 70, 118, and $120 \mathrm{~mm}$.

Therefore, by the saved up experience of tests, theoretical calculations, and trailer tests 2PTS-4-793A, the device allows terms to make fatigue tests in the shortest of such trailers has been developed.

Based on the theoretical calculations and tensometric tests of the 2PTS-4-793A trailer, the device has been developed that provides fatigue testing of these trailers in the shortest possible time.

The movement of the tractor-trailers working in agricultural production is carried out basically on roads with a rough covering.

The device consists of three imitation irregularities, fixed with chains with the ability to adjust their height, which allows you to simulate the movement of a trailer on roads with different macro-profiles. The following parameters were selected as the criteria defining the stress state of the load-bearing elements of the trailer structure: the height of the irregularities, which characterizes the stresses arising in the elements of the frame and body of the trailer; the frequency of overcoming irregularities, characterized by the number of irregularities overcome by the trailer wheel for a certain period; the speed of the trailer, characterized by the absence of resonant modes of trailer oscillation when overcoming irregularities; the duration of fatigue tests, determined by the total mileage of the trailer, which is equivalent to its rated service life under normal conditions; the nature of failures and development of cracks in the elements of load-bearing structures.

The tractor-trailers are used in agriculture move basically on roads with a rough covering ( $70 \div 75 \%$ from the general run). Thus $25-30 \%$ from the general run are necessary on roads to an unsatisfactory condition.

Taking into account it at carrying out of tests for the basic have accepted a microprofile of the road of satisfactory quality. Simulated speed of movement of the trailer is defined by dependence:

$$
V_{\mathrm{tr}}=0.06 \omega l
$$

where $\omega$ is the natural frequency of the trailer, equal $120 \mathrm{~min}^{-1} ; l$ is the step of imitating roughness equal of $0.6 \mathrm{~m}$.

At carrying out forced tests, the main criterion is the height of the imitation unevenness, which was determined by selecting the amplitude characteristics of the stresses in the nodes of the supporting structures of the trailer by the method of electrical strain gauge. The identity of the stress occurrence was achieved when the trailer was moving on a road of satisfactory quality with a gravel surface with an average height of irregularities of $6.5 \mathrm{~cm}$ and when overcoming an imitation irregularity of $8.0 \mathrm{~cm}$ in height. In this case, the average stress in the nodes of the frame and body of the trailer was $\sigma_{0}=76 \mathrm{MPa}$, according to which the number of cycles was determined before the appearance of destruction in the trailer structure according to the formula [14].

$$
N_{t r}=\frac{N_{0} \cdot \sigma_{-1}^{m}}{\sigma_{0}^{m}},
$$

where $N_{0}$ is base number of cycles equal to $2 \cdot 10^{6} ; \sigma_{-1}$ is the average endurance limit for welded frames of $40 \mathrm{MPa} ; \sigma_{0}$ is average statistical design voltage equal to $76 \mathrm{MPa} ; m$ is the cotangent of the angle of the left branch of fatigue in logarithmic coordinates equal to 3 , we find that the number of cycles until the destruction in the construction of the trailer equal $2.9 \cdot 10^{5}$.

Considering that on a wheel 3 imitating roughnesses fasten, the general run of the trailer 
for $2.910^{5}$ cycles will make $132 \mathrm{~km}$ that is equivalent to 8 years of the normal operation of the trailer in economic conditions [14].

Thus, $16.5 \mathrm{~km}$ of the accelerated resource tests of the trailer correspond to 1 year of its operation in real conditions (245 days in a year with a daily run of $30 \mathrm{~km}$ ) and $N_{1}=3.6 \cdot 10^{4}$ loading cycles.

Conditions and the equipment for carrying out the accelerated tests are developed separately, depending on various factors.

One of the basic elements limiting the reliability of the trailer is the welded frame which should provide the necessary durability and reliability of the trailer for all appointed service life - 8 years, taking into account operating repairs.

For the control of experimental data, it is necessary $t_{\text {a. } 1.1}=18120 \mathrm{~km}$ present a settlement time between failures in the form of a certain number of cycles loading of the frame. Considering that the mean time between failures (MTBF) of the frame $t_{\mathrm{a} .1 .1}=18120 \mathrm{~km}$ corresponds to 2.46 years of operation, the settlement number of cycles loading makes trailer frames $N_{2}=2.46 \cdot 3.6 \cdot 10^{4}=0.886 \cdot 10^{5}$ cycles.

For check of results of calculation, we had been carried out resource tests of the bearing system of the trailer 2PTS-5-793D, and the following results (to the failure of the system element) have been received: the left and right longerons - 6.4 years of operation; crossbeam No. 1 - 6.36 years of operation; cross-beam No. 2 - 2.46 years of operation; crossbeam No. 3 - 2.65 years of operation; cross-beams No. 4 , No.5 - 5 years of operation; crossbeam No. 6 - 5.2 years of operation; cross-beam No. 7 - 6.6 years of operation.

The analysis of the results shows that the first refusals of the frame fall to the crossbeam No. 2 (2.46 years of operation). As it has been established, the settlement MTBF of the frame as a whole makes $t_{\mathrm{a} .1 .1}=18120 \mathrm{~km}$ and in recalculation corresponds to 2.46 years of operation, which completely corresponds to test data.

In the production of trailer frames, the most important aspects of selecting and using existing types of rolled products from different steel grades.

Figure 2 [15] shows the fatigue curve of large-scale welded specimens of ordinary quality carbon steel, the parameters of the yield strength ${ }_{\mathrm{s}}$ and the number $N$ of loading cycles. According to the obtained value of ${ }_{s}$ for the manufacture of the frame, you can select rolled steel with the yield strength of steel $\sigma_{\mathrm{s}} \geq \sigma_{\text {s.cal. }}$

In work [15], to take into account technological and operational features, as well as the scale factor, an amendment is introduced for the value of $\sigma_{\mathrm{s}}$ :

$$
\sigma_{\text {red }}=\sigma_{\mathrm{s}} \varepsilon_{\mathrm{c}}
$$

here $\sigma_{\text {red }}$ is the reduced (corrected) yield strength; $\sigma_{\mathrm{s}}$ is the yield strength for a specific rolled steel; $\varepsilon_{\mathrm{c}}=\varepsilon_{1} \varepsilon_{2} \varepsilon_{3} \varepsilon_{4}$ is correction coefficient, where $\varepsilon_{1} \varepsilon_{2} \varepsilon_{3} \varepsilon_{4}$ are coefficients that take into account the effect on the frame, respectively, the machining of its elements; corrosion during trailer operation; frame scale; technological factors of the frame assembly. 


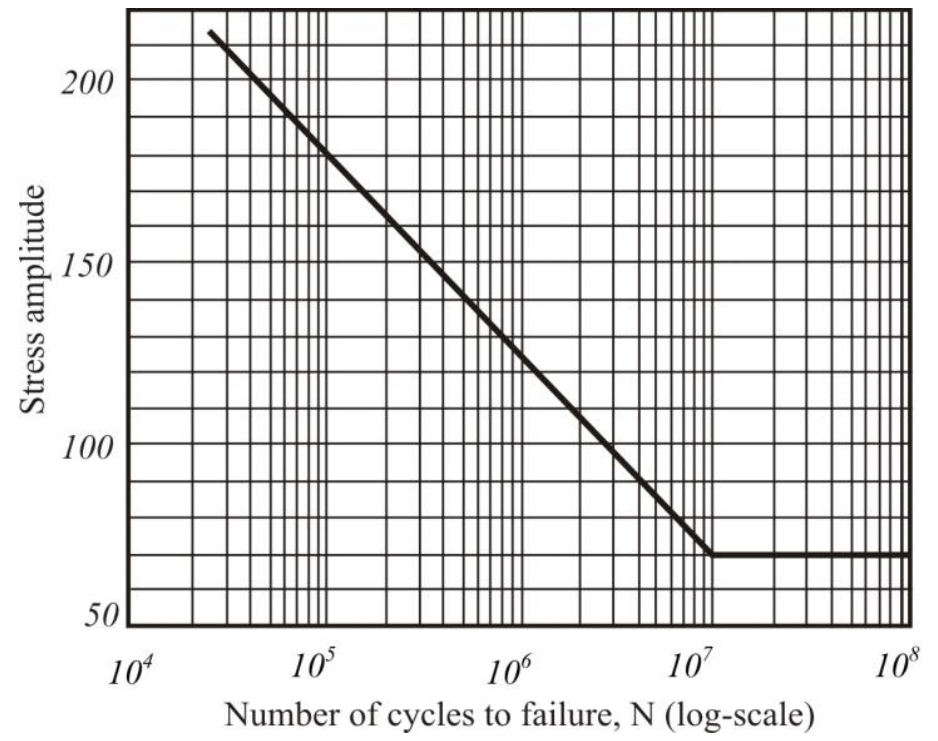

Fig. 2. S-N curve of large-scale welded samples of ordinary quality carbon steel

\section{Results and Discussion}

Analysis of the coefficients $\varepsilon_{1} \div \varepsilon_{4}$ and comparison of their values with experimental data showed that for frame structures of trailers, the correction coefficient is $\varepsilon_{\mathrm{c}}=0.6$.

As an example, consider a frame structure made of rolled steel grade 20 with a yield strength of $\sigma_{\mathrm{s}}=25 \mathrm{MPa}$. The reduced yield stress, determined by the formula (6), $\sigma_{\text {red }}=150$ $\mathrm{MPa}$. For this, the values from the fatigue curve (see Figure 2) determine the number of loading cycles $\mathrm{N} \approx 3 \cdot 10^{5}$. This number corresponds to the calculated value obtained by formula (5) and the experimental data of Central scientific research automobile and automotive engine institute "NAMI" [16].

Thus, at the calculation of a resource of frames of the trailers executed from elements of steel hire of various marks, it is possible to use the formula (6) with correction coefficient $\varepsilon_{\mathrm{c}}$ $=0.6$.

In the theory and practice of estimating machine resources, the following calculation models have also been developed and applied: calculation for tolerance, in which the tolerance field is considered a random process, and calculation for fatigue resistance, in which the damage summation hypothesis is used [16], based on the assumption that damage caused by the stress cycle does not depend on the state of the part at the moment and the previous loading process, but simply adds up with the damage caused by the previous cycles. With a continuous change in stresses corresponding to the operational loads, the basic calculation formula for determining the framing resource can be presented in the form $[16,17]$ :

$$
L_{\mathrm{c}}=a\left[n_{c} \int_{\sigma_{\min }}^{\sigma_{\max }} \frac{b a^{-b} \sigma^{b-1} \exp \left[-(\sigma / a)^{b}\right]}{N_{0}\left(\sigma_{-1} / \sigma\right)^{m}} \mathrm{~d} \sigma\right]^{-1}
$$

where $L_{\mathrm{c}}$ is resource; $\sigma$ is stress; $\sigma_{\max }, \sigma_{\min }$ are maximum and minimum stresses; $\sigma_{-1}$ is 
endurance limit at symmetric cycle; $n_{\mathrm{c}}$ is the average number of cycles per unit of time; $m$ is an indicator of the degree of the fatigue curve; $a$ and $b$ are scale and shape parameters related to the statistical characteristics of the distribution (mathematical expectation $E$ and coefficient of variation $V$ ).

The analysis of a significant number of random stress processes in frames and other metal structures of mobile machines (more than 10000 processes), carried out at Central scientific research automobile and automotive engine institute "NAMI" [17], showed that the coefficient of variation $V$ of the amplitude distributions of complete cycles varies within $0.3 \div 1.2$. In this range of variation of the coefficient $V$, the values of $a$ and $b$ with sufficient accuracy for practice (deviation $\leq 2 \%$ ) are determined by the expressions:

$$
a=\frac{E}{0.55 V^{2}-0.57 V+1.02}, b=V^{-1.079} .
$$

To determine the frame resources by formula (7), a numerical calculation program was developed using MATLAB 7.11.0 (R2010b). In figure 3 shows the dependences of the predicted number $N_{0}$ of stress cycles of the trailer frame on stress $\sigma$ for steel 20 . In the calculation, $\sigma_{\max }=180 \mathrm{MPa} ; N_{0}=2 \cdot 10^{6}$ cycles; $\sigma_{-1}=245 \mathrm{MPa} ; V=0.3 ; E=140 ; m=3.0$.

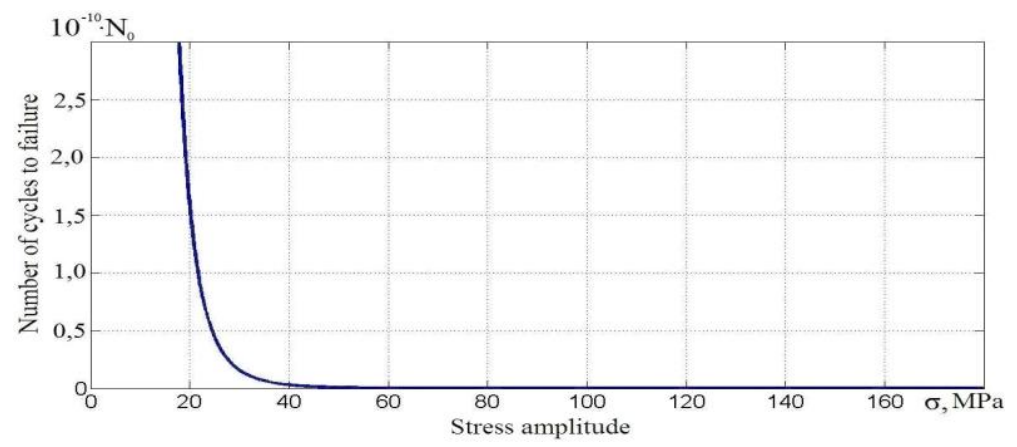

a)

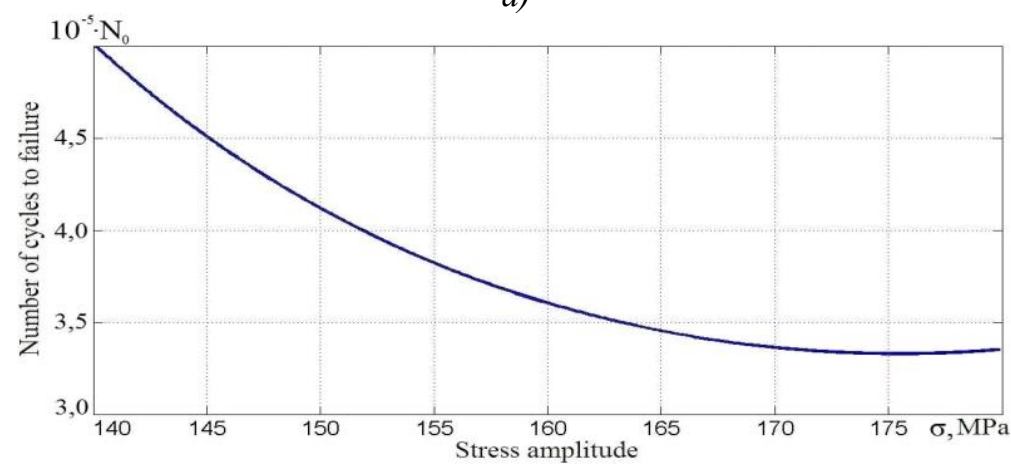

b)

Fig. 3. Fatigue curve of the trailer frame (a) and its fragment of the curve (b)

\section{Conclusion}

According to the results obtained, the predicted resource of the trailer $L_{\mathrm{c}}=0.33 \cdot 10^{6}$ differs by $9 \%$ from the experimental data of Central scientific research automobile and automotive 
engine institute "NAMI" and by $11 \%$ from the value obtained by formula (7).

Thus, based on the calculation of the complex coefficients, the required reliability indicators were calculated, including the probability of non-failure operating (PNFO) and the mean time between failures (MTBF) of the trailer frame elements. The proposed formula with the correction coefficient $\varepsilon_{\mathrm{c}}$, which can be used to calculate the resource of trailer frames made of rolled steel of various grades, and a formula for estimating the durability of a trailer frame, based on the Weibull distribution and the power equation of the fatigue curve.

\section{References}

1. Salimdzhanov R.T., Lebedev O.V., Khakimzyanov R.R. Reliability growth of wheel cars. - p. 338. Tashkent: TARI, (2007).

2. V.I. Patrushev and A.I. Rembeza, Reliability and efficiency in technology. T.5. Reliability design analysis, Under. ed. Moscow: Mechanical Engineering, - p .316. (in Russian) (1988).

3. Methodical instructions. Methods for distributing the reliability requirements for a product between its component parts. Moscow: All-Russian Research Institute of Standardization and Certification in Mechanical Engineering, p 30. (in Russian) (1989).

4. Malinowski V.S., Filjustin A.E., Bagramov M. G. Application of the theory of utility at distribution of requirements to reliability of a product between its elements on the basis of the account of their complexity. Reliability and quality assurance. (11), pp. 7 11. (in Russian). (1988).

5. Lin, Dennis K.J., Simpson, Timothy W., Chen, Wei. Sampling Strategies for Computer Experiments: Design and Analysis, International Journal of Reliability and Applications. 2, (3), pp. 209-240. (2001).

6. Slivinsky E. V., Radin S. Y., Gridchina I. N. Reliability Augmentation of Frames Autotractor Trailers and Semi-Trailers, International Journal of Traffic and Transportation Engineering, p-ISSN: 2325-0062, e-ISSN: 2325-0070, 3 (2): pp. 52-64. doi:10.5923/j.ijtte.20140302.03. (2014);

7. Medvecká-Beňová, S. Strength analysis of the frame of a trailer. Scientific Journal of Silesian University of Technology. Series Transport. 96, pp 105-113. ISSN: 02093324. DOI: https://doi.org/10.20858/sjsutst.2017.96.10. (2017).

8. Trangsrud, C., Law, E., and Janajreh, I. Ride Dynamics and Pavement Loading of Tractor Semi-Trailers on Randomly Rough Roads, SAE Technical Paper 2004-012622, (2004), https://doi.org/10.4271/2004-01-2622.

9. Grzegorz Szczęśniak, Paulina Nogowczyk, Rafał Burdzik. Some basic tips in vehicle chassis and frame design // Journal of Measurements in Engineering, 2, (4), pp. 208214. (2014).

10. Togaev A.A., Shermukhamedov A. A. Method of Calculating the Stress-Strain State of Frame Structures of the Autotractor Trailers for Static Loading Conditions. International Journal of Recent Technology and Engineering (IJRTE), ISSN: 22773878, 8 (5). pp. 4619-4623. January (2020).

11. Togaev A.A., Shermukhamedov A.A. Method of Calculating the Stress-Strain State of Frame Structures of the Tractor Trailers at Various External Influences. International Journal of Mechanical and Production Engineering Research and Development (IJMPERD) ISSN (P): 2249-6890; ISSN (E): 2249-8001, 10, (3), pp. 4729-4740. Jun (2020).

12. Togaev A.A., Shermukhamedov A.A. Method of Calculating the Stress-Strain State of Frame Structures of the Tractor Trailers at Various External Influences, Global 
Journal of Science And Engineering, 4, IOCISET-2020. pp.5-5. DOI: https://doi.org/10.37516/global.j.sci.eng.2020.005a. (2020).

13. Togaev A.A., Shermukhamedov A. A., Salimdzhanov R.T. Substantiation of reliability of the trailer frame at designing, European science review. (1-2). pp. 167170. Austria, (2016).

14. Glushchenko A.D., Slivinsky E.V. Dynamics and durability of transport system for transportation of superficial cargoes. Tashkent: Publishing House of the Uzbekistan Academy of Sciences, p. 116. (1988).

15. Proskuryakov V.B. Dynamics and strength of frames and bodies of transport machines. Leningrad: Mechanical Engineering, p. 232. (in Russian) (1972).

16. Artsibasheva N.N., Dereshov D.S., Beletskaya O.M. Prognosis of trailer frame resource, Proceedings of the Odessa Polytechnic University. 2 (28). pp. 50-53. (in Russian). (2007).

17. Onketena I.A. Calculation of the strength of the tracked tractor frame at the design stage. Dissertation abstract of the candidate of technical sciences, MSTU named after N.E.Bauman. M - p. 17. (in Russian). (1992). 